\title{
SOCIAL CAPITAL AND THE IMPERATIVES OF THE CONCEPT AND LIFE OF UBUNTU IN THE SOUTH AFRICAN CONTEXT
}

\author{
Henry Mbaya ${ }^{1}$ \\ Research Fellow, Practical Theology \& Missiology \\ Stellenbosch University
}

\begin{abstract}
In this paper, I explore the relationship between 'social capital' and the African concept and way of life of ubuntu. I argue that very close parallels exist in the manner that the concept of social capital and African concept and way of life of ubuntu exist and operate. On one hand, just as networks, co-operation, collaboration and mutuality define essential elements that define social capital in the West, on the other hand, the African concept and way of life of ubuntu stress interdependency, communality as is manifested in the spirit of 'brotherhood' and 'brotherliness'. Similarly, just as ubuntu entails a web of relationships in which African hospitality and mutual support characterise African life, so social capital rests on interconnectedness, trust, the elements that drive corporate organisations of the West. Thus both concepts, albeit in different ways, tend to promote participation in life that enhance social welfare. Despite such similarities, however, there are differences between the two concepts. As a Western concept social capital revolves around socioeconomic benefits that the members of the corporate organisations yield, while ubuntu is about African hospitality and mutual support that benefit Africans and those who interact with them.
\end{abstract}

Key Words: Social Capital, African Concept/Ubuntu, Co-operation, Relationships and Interdependency

\section{Introduction}

This study is part of the National Research Foundation (NRF) sponsored research project in the Eastern Cape/KwaZulu-Natal region. ${ }^{2}$ In this paper, I will argue that a close connection exists between social capital and the concept and life of Ubuntu in the South African context. In particular, I will show that the features of social capital as entailed in human networks of trust, loyalty and reciprocity have implications for understanding how the concept and the spirit of Ubuntu are expressed in African South African society.

Dr Henry Mbaya studied History of Christianity at the University of KwaZulu-Natal. He is currently Rector of the Holy Trinity Anglican Parish in Kokstad, South Africa, and a researcher on the NRF funded research project on 'Religious ritual and social capital formation' at Stellenbosch University.

2 The research has been sponsored by the NRF under grant number 65620; a project of the Theology Faculty of Stellenbosch University. However, any opinions, findings and conclusions or recommendations expressed in this material are those of the author and not of the sponsors. 


\section{Defining Social Capital}

Robert Putnam, a Harvard sociology academic, writes that social capital "refers to features of social organisations such as networks, norms, and social trust that facilitate coordination and co-operation for mutual benefit." $\mathrm{He}$ further states that it is about "social networks and the norms of reciprocity associated with them..." In this regard, social capital, therefore centres on a web of 'networks' of human relations and 'partnerships' where they are reciprocated for collective benefit; hence they are considered as essential resources - vital for sustaining the life of associations and or organisations. ${ }^{5}$

Since these networks of human relations are considered to have a critical bearing on the performance of organisations and associations, social capital is viewed in terms of economic utility. ${ }^{6}$ In this respect, Nan Lin defines social capital as "... a collective asset shared by members of a defined group, with clear boundaries, obligations of exchange, and mutual recognition." "Social capital can be measured in terms of trust, whether it is high or low. Hence it is claimed that higher levels of trust enhance the performance of the organisation, inversely low levels of trust diminish the operation of the organisation. ${ }^{8}$ Because much time is invested in raising and maintaining these relationships, social capital is considered as an 'asset' or an 'investment', hence it can be measured in terms of economic utility. Consequently, it is argued that for social capital to be sustained relations of loyalty, trust and reciprocity have to be continually re-inforced. ${ }^{9}$ In this regard, social capital denotes the influence of structures in facilitating certain actions of individuals within the structure. ${ }^{10}$

At the core of social capital, therefore lies five principle features: sharing, mutual obligations, trust, exchange (transactions) and recognition. These are elements that enhance human interactions and relations of collective mutual trust and loyalty. In other words, as Putnam stresses the importance of these elements in the generation "social capital helps to resolve dilemmas of collective action, encouraging people to act in a trustworthy way when they might not otherwise do so." 11

Social capital entails membership. According to D Cohen and L Prusak, it implies "connection: the trust, understanding, and mutuality that support collaborative, cohesive action. It implies commitment to the group and work, co-operation, and the willingness to do more for a job that is not "just a job", ${ }^{12}$ Thus sharing characterise the essence of social capital as reciprocity defines its functional role. More importantly, it is not merely about solidarity, rather it has implications for a shared destiny of a defined group. Hence, social

Putnam, R, 'Bowling Alone: Americas’ Declining Social Capital,' Journal of Democracy 6, no. 1 (1995), p. 65-68.

$4 \quad$ Putnam, R (ed.), 'Introduction'. Democracies in Flux, the Evolution of Social Capital in Contemporary Society, Oxford: Oxford University Press, 2002, p. 3.

5 Lin, N, Social Capital, a Theory of Social Structure and Action, Cambridge: Cambridge University Press, 2001, p. 22

Ibid.

Ibid.

Lin, N, Social Capital, A Theory of Social Structure and Action, p. 146-148. See also Cohen, D and Prusak, L, In Good Company, How Social Capital Makes Organisations Work, Harvard, Boston: Harvard Business School Press, p. 43-45.

Ibid, p. 30-51.

$10 \quad$ Ibid, p. 23.

Putnam, Democracies in Flux, p. 7.

12 Cohen and Prusak, In Good Company How Social Capital Makes Organisations Work p. 61. 
capital is about the people's expression of their identity and the meaning they derive from it.

The question that has to be addressed in this paper is: What imperatives does Ubuntu have for social capital? Or how does social capital relate to the concept of and life in the spirit of Ubuntu? Or to put it differently again, what aspects of the concept of Ubuntu in African community life are particularly beneficial for the generating of the resources for social capital?

Over centuries, there developed in Africa communities a very unique way of expressing African life centred on common norms, values and traditions, which has been defined as Ubuntu. What exactly is Ubuntu?

\section{Networking, Partnerships: The Essence of $\mathbf{U b u n t u}$}

While the concept exists in its variant forms throughout the continent, ${ }^{13}$ African scholars have tended to give it different shades of meanings which really boils down to 'humanness' as opposed to 'animal like behaviour'. ${ }^{14}$ However, in South Africa, the concept of Ubuntu carries its own regional perspective. For instance, Desmond Tutu, Anglican Archbishop Emeritus defines Ubuntu as:

'A person is a person through other persons.' I would not know how to be a human being at all except (that) I learned this from other human beings. We are made for a delicate network of relationships, of interdependence. We are meant to complement each other. All kinds of things go horribly wrong when we break that fundamental Law of our being. Not even the most powerful nation can be completely self-sufficient. ${ }^{15}$

According to this definition, Ubuntu implies a web of human relationships in which Africans are engaged. These relations are characterised by the spirit of interdependence and mutual trust as people rely on each other in everyday life. In his work, Ubuntu, An Ethic for a New South Africa, Augustine Shutte spells out the implications of the ethic of Ubuntu in the context of democratic South Africa. Shutte defines the core of Ubuntu as the dependence of a person on "...personal relations with others to exercise..." with a view to "develop and fulfil those capacities that make one a person."16 African community life experienced "as an interpersonal network of relationships, is thus the fundamental value in traditional Africa thought." 17 Shutte concludes stating that, "One's life, if all goes well, is a continual becoming more of a person through one's interaction with others. Personhood comes as a gift from other."18

Gabriel Setiloane, the African theologian, takes this issue further when he states, "This manner of understanding human personality explains the interplay which takes place when people come into contact or live together." 19 Thus according to Setiloane, "The essence of being is determined by 'participation' in which humans are always interlocked with one another. The human being is not only a 'vital force,' but more: vital

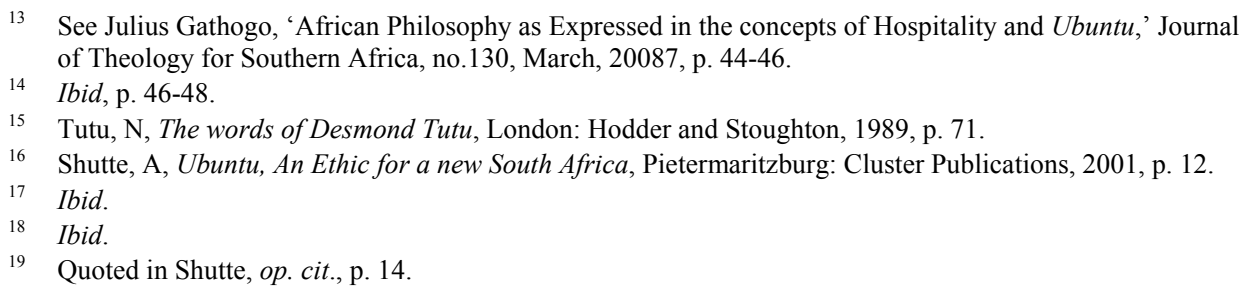


force in participation. ${ }^{20}$ Thus, Tutu, Shutte and Setiloane stress the critical role that human relationships and networks play in defining the role and identity of a person in an African community and the meaning they derive from those associations.

Almost all social scientist scholars concur that human networks which display trust, loyalty and reciprocity yield social capital. ${ }^{21}$ Though the studies conducted by Anirudh Krishna and Norman Uphoff directly apply to the Indian context, nonetheless they also have some relevance to ours. In this regard they note that "It is not the networks per se that are important but the meanings these networks hold for their members and the possibilities for collective action and personal benefit they open up." ${ }^{22}$ In short, networks of human relationships, the core of social capital, give associations their meaningful purpose of existence.

Again, according to Tutu, Ubuntu denotes a delicate network of relationships that gives meaning and purpose to the operation of the African community. ${ }^{23}$ Unlike the Western concept that stresses individualism, Ubuntu entails the person's identity and fulfilment within rather than versus the community. These relationships are the lifeline of the society - as the persons not only derive their identity but also find fulfilment in these links. The destiny of the entire community is thus intricately bound to that of a person.

Shutte rightly notes that networks of relationships define the spirit of Ubuntu as each person exists only as a part of the community in which he is fully involved and to which he is fully committed. ${ }^{24}$ Hence, networks of human relationships are integral to the order and rhythm of life in the African community. As Don Cohen and Laurence Prusak state, "Networks help people develop their identities". ${ }^{25}$ More importantly, so they argue, they help forge membership, which entails connection, "the trust, understanding and mutuality that support collaborative, cohesive action" ${ }^{, 26}$ are engendered.

\section{Indaba/Imbizo: African Structures of Participation}

In African communities, collaborative activity becomes possible precisely because of the existence of the traditional participatory structures that promote consensus on essential matters facing African communities. The institution of Indaba among the Zulu or Imbizo's amongst the Xhosa (both terms for communal assemblies or gatherings) for example, reflect co-operative efforts to reach a common mind on critical issues, such as crime, confronting a community. In these gatherings an attempt is made for maximum participation. As Shutte states, "Discussion must continue until unanimity is achieved, a really common mind and heart. This is the only adequate sign that the truth of the matter has been discovered. ${ }^{27}$ In this respect, E Ostrom makes a relevant point with regard to organisations when he says that co-operative activity becomes more likely and successful

$20 \quad$ Ibid, p. 12.

21 See for instance Cohen, D and Prusak, L, In Good Company, How Social Capital Makes Organisations Work, p. 28-31.

22 Krishna, A and Uphoff, N, 'Mapping and measuring social capital through assessment of collective action to conserve and develop watersheds in Rajasthan, India' in Grootaert, $\mathrm{C}$ and Van Bastelaer, $\mathrm{T}$ (eds.). The Role of Social Capital in Development, An Empirical Assessment, Cambridge: Cambridge University Press, 2002, p. 100.

23 Tutu, The words of Desmond Tutu, p. 24.

24 Shutte. Ubuntu, an Ethic for a New South Africa, p. 60.

Cohen and Prusak, In Good Company How Social Capital Makes Organisations Work, p. 61

6 Ibid.

27 Shutte, Ubuntu, an Ethic for a New South Africa, p. 28. 
when individuals in a community abide by the rules that have been made through consultation rather than imposed from outisde. ${ }^{28}$ Dietlind Stolle notes that associations like these "contribute to the emergence of societal norms and generalised values." 29

Spurred by trust and the loyalty of the members, these communal gatherings are attempts to promote co-operative efforts with a view to advancing the well-being of the local communities. The more regularly these meetings occur - the greater they intensify the bonds of brotherhood amongst the people. The kind of relationships involved here is similar to what Anthony Bebbington and Thomas Carroll in their studies relating to the Andes call bonding and bridging relationships. ${ }^{30}$ In these formal gatherings information is shared which has the capacity to influence the life of the members of the community. "Underlying such a discussion is the conviction that the community has a common mind, a common heart", asserts Shutte. ${ }^{31}$

Shutte rightly maintains that "Achieving a common mind and heart on a specific issue builds up the community as such intensifying the spirit of solidarity of its members. ${ }^{32}$ In this regard, Putnam's observation regarding the role of voluntary organisations in democratic societies in the USA seems to have some relevance to our case. He noted, "These associations of participation promote and enhance collective norms and trust, which are central to the production and maintenance of well-being. ${ }^{, 33}$ The social cohesion of African communities thus depends very much on such structures. Since so much time is invested in the operation of these structures, and a sense of loyalty is fostered, they are important resources for mobilising collective action for the communities.

\section{Ubuntu and Social Security: Interdependence - African Hospitality}

Essentially social capital is about the well-being of the members of a group or community - where all stand to benefit from the assets accruing from relationships of trust, loyalty and reciprocity. Shutte rightly suggests that Ubuntu provides social security to all its members in a community precisely because behind this philosophy lies the idea that "persons develop as persons the more they are subject to a certain kind of influence of others... [in community] ${ }^{34} \mathrm{He}$ maintains that the close relations in the African community facilitates a deeper sense of integration of the person, which fosters selfdetermination, which in turn opens up for the person broader choices in life which lead to personal fulfilment. ${ }^{35} \mathrm{He}$ attributes "the source of this power" to "a certain kind of dependence on other persons" - Ubuntu. ${ }^{36}$ This "certain kind of dependence' to which Shutte refers has the capacity to exert influence in society which is critical to the 'bonding and bridging' of relationships - the hallmarks of social capital.

28 Krishna, A and Uphoff, N, 'Mapping and measuring social capital through assessment of collective action to conserve and develop watersheds in Rajasthan, India' in Grootaert, $\mathrm{C}$ and Van Bastelaer, T (eds.), The Role of Social Capital in Development, An Empirical Aassessment, p. 115.

29 Stolle, D, 'The Sources of Social Capital' in Hooghe, M and Stolle, D, (eds.), Generating Social Capital, Civil society and Institutions in Comparative Perspective, New York: Palgrave MacMillan, 2003, p. 20.

30 Bebbington, AJ and Carroll, TF, 'Induced social capital and federations of the rural poor in the Andes, the role of social capital in development, p. 237.

Shutte, Ubuntu, an Ethic for a New South Africa, p. 28.

Ibid.

Lin, Social Capital, p. 23.

Shutte, Ubuntu, an Ethic in a New South Africa, p. 61.

Ibid.

36 Ibid. 
In his study, Townships and the Spirit of Ubuntu, Mike Telschow points out that "Ubuntu expresses an African philosophy of life that one may perhaps describe as brotherliness, solidarity and togetherness." 37 In African context these values find expression in the spirit of hospitality. Nelson Mandela, a former State President, expressed how the spirit of Ubuntu was lived in South Africa:

A traveller through our country would stop at a village, and he [or she] didn't have to ask for food or for water. Once he stops, the people give him [or her] food, and entertain him [or her]. That is one aspect of Ubuntu [and generally of African hospitality] but Ubuntu has various aspects. Ubuntu does not mean that people should enrich themselves. The question therefore is: Are you going to do so in order to enable the community around you to improve? ${ }^{38}$

African hospitality thus reflects the principle and the spirit in which Africans are engaged in networks of human relationships - which essentially are propelled by family, clan and tribal ties. African hospitality is at the core of the spirit of Ubuntu. African hospitality is accorded on the principle that the one who receives it will likewise reciprocate it in time of the need of the other person - thus expressing the spirit Ubuntu "I am because we are." Similarly, in their study of liturgy and ritual and poverty in South Africa, Johan Cilliers and Cas Wepener extolled African hospitality as an element that has important implications in generating social capital. ${ }^{39}$ Similarly, as Gathogo states, "[ It ]is a powerful tool for glueing the community [which can also refer to the whole world as a global village] together, as well as the community with ancestors and God."

Since as Gathogo rightly argues - that African hospitality acts as an important tool to bring the African community together, ${ }^{41}$ it is an important feature that can facilitate social capital - for social capital, after all, entails values or norms that draw people together. It is about the extent to which people are connected together and the manner in which those ties enhance their well-being.

Essentially, social capital, like Ubuntu, is about human solidarity - the extent to which organisations or associations enforce and display a sense of loyalty and trust among its members, a sense of belonging to its members. Similarly, the way of Ubuntu is about 'brotherliness' 'brotherhood', a quality that not only displays identity but more importantly defines the meaning of existence for its members. As social capital is about social ties, so Ubuntu is about interconnectedness and interdependence.

However, social capital and Ubuntu are not one and the same thing. Unlike social capital where the trust and loyalty can be measured viz $\grave{a}$ vis the performance of the members of the organisation in terms of its economic utility, Ubuntu cannot be quantified nor enumerated since the way of Ubuntu does not operate in Western economic terms but rather in African terms of the 'dignity' or 'indignity' of the people. Hence as a philosophy, Ubuntu is lived or experienced - rather than mechanically 'generated.'

While social capital is confined to specific social units in the corporate organisations, normally people with similar interests or goals, as a philosophy - Ubuntu is more

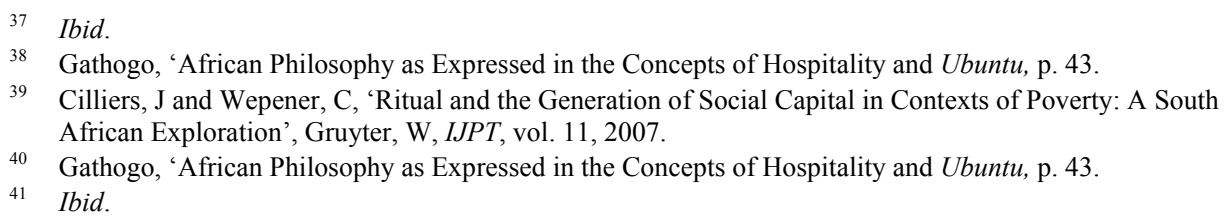


encompassing - its spirit embracing persons in African communities and beyond to people of other racial groups, as well who also must benefit from African hospitality.

However, some negative effects that social capital produce in society have also been noted. For instance, Cohen and Prusak noted how strong social loyalty and trust of the Nazi Brown Shirts during Adolf Hitler's reign normalised their aberrant behaviour. ${ }^{42}$ Likewise Gathogo noted that national or tribal or clan affinities, where trust and loyalty rule, may be abused to serve anti-social behaviour with catastrophic consequences. To illustrate this Gathogo draws our attention to the Rwanda genocide of $1994 .^{43}$

\section{Conclusion}

In conclusion, in the preceding discussion I have tried to show the bearing of critical elements of social capital, notably networks of human relationships propelled by mutuality, trust and loyalty have on the understanding of Ubuntu. In particular, I argued that structures of participation, such as Indaba, or Imbizos play a significant role in enhancing collective action. Likewise, I argued that African hospitality expresses the spirit of Ubuntu, which in fact is a principal asset that entails social security in the African community. Finally, I argued that social capital and Ubuntu are about solidarity, 'brotherliness', a spirit that undergirds networks and partnerships - the cardinal principles of social capital.

However, I also drew attention to the fact that blind loyalty and trust can sometimes yield anti-social behaviour amongst organised groups or within African tribal societies, where the spirit of Ubuntu can be distorted for ideological purposes. In view of what I have put before you could it not be said that the traditions, norms and values of Ubuntu already in place in Africa today are developing and facilitating social capital?

\section{BIBLIOGRAPHY}

Bebbington, AJ and Carroll, TF 2002. 'Induced social capital and federations of the rural poor in the Andes', Grootaert, C and Van Bastelaer, T (eds.). The Role of Social Capital in Development, an Empirical Assessment, Cambridge: Cambridge University Press.

Cilliers, J and Wepener, C 2007. 'Ritual and the Generation of Social Capital in Contexts of Poverty: A South African Exploration', Gruyter, W. IJPT, vol. 11.

Cohen, D and Prusak, L 1992. In Good Company, How Social Capital Makes Organisations Work, Boston: Harvard Business School Press.

Gathogo, J 2008. 'African Philosophy as Expressed in the Concepts of African hospitality and Ubuntu', Journal of Theology for Southern Africa, no. 130.

Hooghe, M and Stolle, D (eds.) 2003. Generating Social Capital, Civil Society and Institutions in Comparative Perspective, New York: Palgrave MacMillan.

Krishna, A and Uphoff, N 2002. 'Mapping and measuring social capital through assessment of collective action to conserve and develop watersheds in Rajasthan,

42 Cohen and Prusak, In Good Company How Social Capital Makes Organisations Work, p. 15.

43 Gathogo, op. cit., p. 47. 
India' in Grootaert, $\mathrm{C}$ and Van Bastelaer, T (eds.). The Role of Social Capital in Development, an Empirical Assessment, Cambridge: Cambridge University Press.

Lin, N 2001. Social Capital, a Theory of Social Structure and Action, Cambridge: Cambridge University Press.

Putnam, RD 1995. 'Bowling Alone: American's Declining Social Capital'. Journal of Democracy, no. 6:65-78.

Putnam, RD (ed.) 2002. Democracies in Flux, the Evolution of Social Capital in Contemporary Society, Oxford: Oxford University Press.

Shutte, A 2001. Ubuntu, an Ethic for a New South Africa, Pietermaritzburg: Cluster Publications.

Stolle, D 2003. 'The Sources of Social Capital' in Hooghe, M and Stolle, D (eds.). Generating Social Capital, Civil society and Institutions in Comparative Perspective, New York: Palgrave MacMillan.

Telschow, M 2003. Townships and the Spirit of Ubuntu, Cape Town: Clifton Publications.

Tutu, N 1989. The words of Desmond Tutu, London: Hodder and Stoughton. 